\title{
Challenges associated with bariatric surgery - a multi-center report
}

\author{
Tomasz Stefura ${ }^{1}$, Oksana Skomarovska ${ }^{1}$, Michał Wysocki², Michał Janik³ ${ }^{3}$ Marta Krzysztofik ${ }^{1}$, Maciej Walędziak ${ }^{3}$, \\ Michał Pędziwiatr², Piotr Kowalewski ${ }^{3}$, Piotr Małczak², Katarzyna Bartosiak², Mateusz Rubinkiewicz², \\ Michał Orłowski ${ }^{3}$, Maciej Matłok ${ }^{4}$, Mateusz Wierdak², Katarzyna Major ${ }^{5}$, Piotr Myśliwiec ${ }^{6}$, Jacek Szeliga \\ Andrzej Budzyński², Piotr Major ${ }^{2}$ \\ ${ }^{1}$ Students' Scientific Group at $2^{\text {nd }}$ Department of General Surgery, Jagiellonian University Medical College, Krakow, Poland \\ ${ }^{2} 2^{\text {nd }}$ Department of General Surgery, Jagiellonian University Medical College, Krakow, Poland \\ ${ }^{3}$ Department of General, Oncological, Metabolic and Thoracic Surgery, Military Institute of Medicine, Warsaw, Poland \\ ${ }^{4}$ Subcarpathian Obesity Treatment Center in the PRO-FAMILIA Specialist Hospital, Rzeszow, Poland \\ ${ }^{5}$ Faculty of Health Sciences, Jagiellonian University Medical College, Krakow, Poland \\ ${ }^{6}$ Department of General and Endocrinological Surgery, Medical University of Bialystok, Bialystok, Poland \\ ${ }^{7}$ Department of General, Gastroenterological, and Oncological Surgery Collegium Medicum, Nicolaus Copernicus University, Torun, \\ Poland
}

Videosurgery Miniinv 2019; 14 (4): 526-531 DOI: https://doi.org/10.5114/wiitm.2019.81370

\begin{abstract}
Introduction: Due to the constantly growing demand for surgical treatment of obesity, it is necessary to create new bariatric centers and further improve presently active ones.

Aim: To identify which stages of conducting peri-operative care and organizing a modern bariatric center currently pose the greatest challenge.

Material and methods: An anonymous survey was designed and distributed to bariatric surgeons. Our questionnaire was divided into three parts: demographic characteristics, difficulties associated with peri-operative care for bariatric patients (assessed on a scale of 1-5) and difficulties associated with organization or running of bariatric centers in which participants are currently working (assessed on a scale of 1-5).

Results: Overall, 70 surgeons and surgical residents from 17 surgical centers participated in our survey. The most difficult element of the pre-operative care was compliance with the recommendation to cease smoking (3.47 \pm 1.28$)$. The most difficult obstacle during the postoperative care period was implementation of the enhanced recovery after surgery (ERAS) protocol (2.27 \pm 1.31$)$. Funding for the bariatric treatment was obtained exclusively from the National Health Fund by 60 (85.7\%) respondents working in 15 different bariatric centers (88.2\%). Among elements of bariatric infrastructure access to operating theater equipment sized for morbidly obese patients was reported to be the most difficult $(3.8 \pm 1.68)$.

Conclusions: Pre-operative recommendations including smoking, physical activity or weight loss, as well as introducing ERAS protocol based peri-operative care, are difficult to execute in bariatric departments. Future specialized bariatric centers should be included in the centralized register and equipped with specialized infrastructure for morbidly obese patients.
\end{abstract}

Key words: obesity, bariatric surgery, peri-operative care, enhanced recovery after surgery, organizational difficulties.

\section{Address for correspondence}

Piotr Major, $2^{\text {nd }}$ Department of General Surgery, Jagiellonian University Medical College, 21 Kopernika St, 30-501 Krakow, Poland,

e-mail: piotr.major@uj.edu.pl 


\section{Introduction}

Low risk of postoperative complications and beneficial outcomes after the surgical treatment of obesity depend as much on the course of the operation as on the administration and management of the department conducting the preparations and peri-operative care. Organization of a state-of-theart bariatric center should be conducted in accordance with modern, acceptable standards [1]. However, the creation and running of such a center is fraught with multiple difficulties.

First approaches to bariatric surgery in Poland were conducted in the 1970s using classical laparotomy (jejunoileal bypass). Legitimate introduction of surgical treatment of obesity in Poland took place in the 1990s and in 2001 the Polish Association for Prevention and Treatment of Obesity joined the International Federation for the Surgery of Obesity and Metabolic Disorders (IFSO) [2]. Currently multiple surgical centers in Poland perform bariatric operations. This resulted in creation of the Metabolic and Bariatric Surgery Chapter of the Polish Surgical Society, which so far has issued two editions of guidelines (2009 and 2016) for surgical treatment of obesity intended for Polish surgeons [3, 4].

The number of bariatric procedures performed yearly is steadily growing $[5,6]$. Nevertheless, it seems that there is constantly a great disproportion between the number of patients requiring surgical treatment of obesity and those being referred to the bariatric surgeon [7]. Due to growing demand for surgical treatment of obesity, there is a need for creating and improving bariatric centers in our country. Therefore, an assessment of current problems affecting bariatric treatment seems to be valid.

\section{Aim}

Our objective was to identify which stages of peri-operative care and establishing a modern bariatric center are currently the greatest challenge in a developed European country.

\section{Material and methods}

\section{Study design}

An anonymous survey was designed to assess current difficulties in creating a bariatric center and managing bariatric patients in surgical departments. The questionnaire included multiple choice and open-ended questions. The survey was distributed to medical doctors exclusively using a mailing list and the official website of the Metabolic and Bariatric Surgery Chapter of the Polish Surgical Society, between January and June, 2018. Comprehensive instructions on how to complete the survey were included at the beginning of the questionnaire.

\section{Inclusion and exclusion criteria}

The study group included surgeons and general surgery residents working in a bariatric center. We excluded physicians and residents with different specializations than general surgery, medical interns, medical students and other health-care professionals.

\section{Survey}

Our questionnaire was divided into three parts: demographic characteristics, difficulties associated with peri-operative care for bariatric patients, and organization and running of bariatric centers in which participants are currently working.

- The first part gathered data on age, sex, stage of surgical training - resident/specialist, voivodeship, experience in surgery (years) and experience in bariatric surgery (years) of the participant.

- Questions in the second part verified difficulty level (on a scale of 1-5) of preoperative management and included: obtaining specialist, psychological or dietary consultations, achieving pre-operative weight reduction, the patient's compliance with pre-operative recommendations for physical activity and cessation of tobacco smoking, access to a support group for bariatric patients, organizing educational lectures and providing patients access to educational materials, leaflets, diaries, etc. It also included questions related to the difficulty level (on a scale of 1-5) of various elements of post-operative care, particularly: early mobilization of patients, implementation of the ERAS protocol, early supply of oral fluids, pain control, postoperative nausea and vomiting control, and control of potential gastro-intestinal leak. Additionally, we requested information on the schedule of follow-up visits and rate of participation during the first post-operative year and after the first year.

- The third part of the survey requested information on the reference level of the hospital, type of currently performed bariatric operations, num- 
ber of bariatric operations performed yearly by the center, funding (National Health Fund or commercial), accessibility of the bariatric infrastructure in the surgical ward and operating theater adapted to the needs of bariatric patients including (on a scale of 1-5): patients' rooms (beds, armchairs), bathrooms and toilets, means of transport (wheelchairs, prams, lifters, bariatric ambulance), endoscopy unit, computed tomography machine adjusted to superobese individuals and operating room equipment (bariatric op-

Table I. Difficulty in achieving individual elements of preoperative care

\begin{tabular}{|lc|}
\hline Element of perioperative care & Mean difficulty (1-5) \\
\hline $\begin{array}{l}\text { Organization of specialist } \\
\text { consultation }\end{array}$ & $2.17 \pm 1.06$ \\
\hline $\begin{array}{l}\text { Organization of psychological } \\
\text { consultation }\end{array}$ & $2.46 \pm 1.55$ \\
\hline $\begin{array}{l}\text { Organization of dietary } \\
\text { consultation }\end{array}$ & $3.32 \pm 1.4$ \\
\hline Achieving preoperative weight loss & $3.18 \pm 1.08$ \\
\hline $\begin{array}{l}\text { Compliance with preoperative } \\
\text { recommendations concerning } \\
\text { physical activity }\end{array}$ & $3.47 \pm 1.28$ \\
\hline $\begin{array}{l}\text { Compliance with preoperative } \\
\text { recommendations concerning } \\
\text { stopping smoking tobacco }\end{array}$ & $2.53 \pm 1.35$ \\
\hline $\begin{array}{l}\text { Organization of access to a support } \\
\text { group for bariatric surgery patients }\end{array}$ & $2.38 \pm 1.2$ \\
\hline $\begin{array}{l}\text { Organization of educational } \\
\text { lectures }\end{array}$ & $2 \pm 1.17$ \\
\hline $\begin{array}{l}\text { Providing access to educational } \\
\text { materials, leaflets, diaries, etc. }\end{array}$ & \\
\hline
\end{tabular}

Table II. Challenges occurring in the postoperative period after bariatric treatment

\begin{tabular}{|lc|}
\hline Postoperative problem & Mean difficulty (1-5) \\
\hline $\begin{array}{l}\text { Early mobilization of patients after } \\
\text { the procedure }\end{array}$ & $1.74 \pm 0.77$ \\
\hline Implementing ERAS protocol & $2.27 \pm 1.31$ \\
\hline Early supply of oral fluids & $1.62 \pm 0.77$ \\
\hline Pain control & $1.73 \pm 0.7$ \\
\hline $\begin{array}{l}\text { Postoperative nausea and vomiting } \\
\text { control }\end{array}$ & $1.81 \pm 0.77$ \\
\hline $\begin{array}{l}\text { Control of potential gastro-intesti- } \\
\text { nal leak }\end{array}$ & $1.5 \pm 0.66$ \\
\hline
\end{tabular}

erating table, mattress, patient fastening system, bariatric instruments for laparoscopic surgery).

\section{Ethical considerations}

The study was performed in accordance with the ethical standards laid down in the 1964 Declaration of Helsinki and its later amendments (Fortaleza). Participants were informed about the aim of the study and informed consent was obtained electronically prior to the beginning of the survey.

\section{Results}

\section{Participants}

Overall, 70 surgeons and surgical residents from 17 surgical centers participated in our survey. The study group included 57 (81.4\%) males and 13 (18.6\%) females. Mean age was $41.04 \pm 11.18$ years. The group of respondents included $51(72.9 \%)$ surgeons and $19(27.1 \%)$ residents in training in general surgery. Mean experience at work as a general surgeon among respondents was $15.31 \pm 11.78$ years. Participants were actively involved in surgical treatment of obesity for $7.39 \pm 5.91$ years on average.

\section{Peri-operative care}

The most difficult element of the pre-operative care was compliance with the recommendation to cease smoking ( $3.47 \pm 1.28$ ), followed by compliance with the recommendation to increase physical activity $(3.18 \pm 1.08)$ and achieving pre-operative weight loss (3.06 \pm 0.94$)$ (Table I). The most difficult obstacle during postoperative care period was implementation of the ERAS protocol $(2.27 \pm 1.31)$, followed by the management of postoperative nausea and vomiting $(1.81 \pm 0.77)$ and early mobilization of patients (1.74 \pm 0.77$)$ (Table II). Routine long-term follow-up examinations after bariatric surgery were conducted by $56(80 \%)$ participants. Usually the schedule of follow-up examinations is designed individually for each patient's needs $(28-40 \%)$. Participants reported a mean rate of $68.78 \pm 30.11 \%$ of patients willing to attend follow-up examinations during the first year following the procedure and $48.08 \pm 26.3 \%$ after the first year following the procedure.

\section{Bariatric center}

Most participants (49-70\%) work in a hospital with a reference level of three (academic center). 
It was followed by participants from hospitals with a reference level of two (10-14.3\%) and one (8$11.4 \%)$. The most commonly performed operation was laparoscopic sleeve gastrectomy (67-95.7\%), followed by laparoscopic Roux-en-Y gastric bypass (43-61.4\%) and one-anastomosis gastric bypass (mini gastric bypass) (17-24.3\%). Most participants in our survey worked in a bariatric center performing 300-400 bariatric operations a year (23-32.9\%). Funding for the bariatric treatment was obtained exclusively from the National Health Fund by 60 $(85.7 \%)$ respondents working in 15 different bariatric centers (88.2\%). Only 7 (10\%) participants from 2 (11.7\%) institutions conducted bariatric treatment funded commercially and by the National Health Fund, whereas $3(4.3 \%)$ did not state the source of funding in their center. Among elements of bariatric infrastructure access to operating theater equipment sized for morbidly obese patients was reported to be the most difficult $(3.8 \pm 1.68)$. It was followed by access to computed tomography $(3.62 \pm 1.5)$ and patients' rooms adapted to the needs of bariatric patients $(3.6 \pm 1.6)$ (Table III).

\section{Discussion}

Our survey-based study investigated current problems associated with bariatric treatment. The designed questionnaire assessed potential difficulties occurring during both the course of the peri-operative care and organizational or administrative problems arising concurrently with managing a modern bariatric center in a developed European country.

The presented study is a result of the cooperation between multiple bariatric centers. Surgeons who participated in our study reported substantial difficulties associated with achieving compliance among bariatric patients with pre-operative recommendations, introducing modern peri-operative care protocols and access to operating theater equipment adapted appropriately for morbidly obese patients.

Respondents to our survey reported significant difficulties with convincing patients of the necessity to stop smoking prior to the bariatric procedure. According to Haskins et al., smoking is a significant risk factor for postoperative morbidity, including among bariatric patients [8]. Available data show that in order to achieve reduction in wound healing, cessation of smoking must take place at least 3 to 4 weeks before the operation [9]. It seems that patients should
Table III. Accessibility of bariatric infrastructure

\begin{tabular}{|lc|}
\hline Element of bariatric infrastructure & $\begin{array}{c}\text { Mean accessibility } \\
(1-5)\end{array}$ \\
\hline $\begin{array}{l}\text { Patients' rooms adapted } \\
\text { to the needs of bariatric patients }\end{array}$ & $3.6 \pm 1.6$ \\
\hline $\begin{array}{l}\text { Bathrooms and toilets adapted } \\
\text { for the needs of bariatric patients }\end{array}$ & $3.43 \pm 1.56$ \\
\hline $\begin{array}{l}\text { Means of transport adapted } \\
\text { to bariatric patient }\end{array}$ & $3.2 \pm 1.43$ \\
\hline Endoscopic unit & $3.41 \pm 1.67$ \\
\hline $\begin{array}{l}\text { Computer tomography machine } \\
\text { adapted to bariatric patients }\end{array}$ & $3.62 \pm 1.5$ \\
\hline $\begin{array}{l}\text { Operating theater equipment sized } \\
\text { for bariatric patients }\end{array}$ & $3.8 \pm 1.68$ \\
\hline
\end{tabular}

be advised to stop smoking tobacco at every point of pre- or postoperative care [10]. Bariatric surgery candidates who preoperatively used tobacco may also undergo additional treatment to achieve smoking cessation, which often has a beneficial impact on the overall health as well as the postoperative outcomes [11].

Introducing an ERAS-based peri-operative care protocol seems to be particularly challenging in bariatric centers. Implementing the ERAS protocol is often associated with difficulties and obstacles, usually resulting from the traditional approach to peri-operative care, and reluctance to change it among senior surgeons who are usually managing surgical wards and bariatric centers [12]. A survey-based study by Martin et al. indicated that the main barriers associated with introducing the ERAS protocol were time restraints, reluctance to change and logistical problems arising from changing surgical wards' organization [13]. Implementation of the ERAS protocol significantly improves surgical outcomes in upper gastrointestinal surgery [14-16]. The positive impact becomes more apparent with increasing compliance with particular components of peri-operative care $[17,18]$. The ERAS protocol also has the potential to safely contribute to reducing costs of surgical treatment $[19,20]$.

According to the results of our survey, most bariatric operations in Poland seem to be funded by the National Health Fund, which may limit the number of procedures performed and obtaining necessary equipment and furnishing of the wards. The main reason for that is that in Poland there are no separate funds for bariatric procedures and the amount of money reimbursed is limited. 
Bariatric centers often propose different operations, different peri-operative care protocols and different follow-up visits regimens after the procedure. Introducing an accreditation system for bariatric centers in Poland may positively influence surgical outcomes by standardization of important elements of management [21]. Creating a centralized registry of bariatric surgery centers in USA according to Kuo et al. did not result in impaired access to care. The authors even observed an improvement in access to bariatric surgery among some underserved populations [22]. Furthermore, a centralized accreditation system in Poland would create multiple scientific opportunities for further survey-based studies or multi-center bariatric clinical trials on a large groups of patients, which in the past often led to acquiring new, statistically significant and more precise results [23].

Organization of a surgical center adopted to the needs of obese patients is challenging [24]. Both pre-operative and post-operative care differ significantly in morbidly obese individuals [25]. Adaptations for bariatric patients which should be incorporated into a modern bariatric center include safe means of patient transport, techniques of anesthesia and intra-operative exposure, postoperative recovery and measures to assure postoperative patient safety, hygiene, and comfort [26, 27]. This requires appropriate staffing, operating room and hospital facilities. Results of the survey conducted by Nguyen et al. among bariatric surgeons of the United States of America in 2004 stressed the need for appropriate equipment and facilities capable of handling the morbidly obese and credentialing of bariatric surgeons [28]. Our study indicates that obtaining specialized equipment of an operating theater sized for bariatric patients is particularly challenging in a clinical setting.

This study is associated with several limitations. Firstly, the overall number of 70 respondents is relatively low. Secondly, we concentrated only on European bariatric departments, so it may be difficult to generalize our results to other continents. The third limitation results from the lack of precise comparison between peri-operative care protocols between centers, which might cause differences in experienced difficulties. However, bariatric centers participating in our survey based their peri-operative care protocols on recommendations included in recently published Polish guidelines, so the course of peri-operative care should be comparable [4]. Unfortunately, the data gathered by our survey are lim- ited. Researchers studying the organizational status of bariatric surgery in Poland in the future may consider a more comprehensive data collection method.

\section{Conclusions}

Pre-operative recommendations including smoking, physical activity or weight loss are difficult to execute. Introducing ERAS protocol based peri-operative care in bariatric departments remains difficult in reality. We believe that efforts should be made to implement at least components of this approach, due to the currently confirmed beneficial impact of the ERAS protocol on outcomes, including among bariatric patients. Further research could identify potential ways to improve compliance with preoperative recommendations and means to overcome difficulties associated with introducing ERAS. The development of specialized bariatric centers, which would be included in the centralized register and equipped with specialized infrastructure for morbidly obese patients, seems to be the next step to improve post-operative results.

\section{Conflict of interest}

The authors declare no conflict of interest.

\section{References}

1. Sztuczka E, Żukowska W, Jackowski M, et al. Recommendations for the standards of equipping of the Bariatric and Metabolic Surgery Center. Pol J Surg 2018; 90: 42-6.

2. Pardela M, Wiewióra M, Sitkiewicz T, Wylezoł M. The progress in bariatric surgery. J Physiol Pharmacol 2005; 56: 35-44.

3. Wyleżoł M, Paśnik K, Dąbrowiecki S, et al. Polish recommendations for bariatric surgery. Videosurgery Miniinv Suppl 2009; 4: 8 .

4. Budzyński A, Major P, Głuszek S, et al. Polskie rekomendacje w zakresie chirurgii bariatrycznej i metabolicznej. Med Prakt Chir 2016; 6: 13-25.

5. Walędziak M, Różańska-Walędziak A, Kowalewski PK, et al. Present trends in bariatric surgery in Poland. Videosurgery Miniinv in press; DOI: https://doi.org/10.5114/wiitm.2018.77707.

6. Janik MR, Stanowski E, Paśnik K. Present status of bariatric surgery in Poland. Videosurgery Miniinv 2016; 11: 22-5.

7. Major P, Stefura T, Jezierska-Kazberuk M, et al. The knowledge of Polish primary care physicians about bariatric surgery. Videosurgery Miniinv 2016; 11: 164-70.

8. Haskins IN, Amdur R, Vaziri K. The effect of smoking on bariatric surgical outcomes. Surg Endosc 2014; 28: 3074-80.

9. Wong J, Lam DP, Abrishami A, et al. Short-term preoperative smoking cessation and postoperative complications: a systematic review and meta-analysis. Can J Anaesth 2012; 59: 268-79. 
10. Myers K, Hajek P, Hinds C, McRobbie H. Stopping smoking shortly before surgery and postoperative complications: a systematic review and meta-analysis. Arch Intern Med 2011; 171: 983-9.

11. Adams CE, Gabriele JM, Baillie LE, Dubbert PM. Tobacco use and substance use disorders as predictors of postoperative weight loss 2 years after bariatric surgery. J Behav Health Serv Res 2012; 39: 462-71.

12. Jiang Z, Li J. Current status and prospect of enhanced recovery after surgery. Zhonghua Wai Ke Za Zhi 2016; 54: 6-8.

13. Martin D, Roulin D, Grass F, et al. A multicentre qualitative study assessing implementation of an Enhanced Recovery After Surgery program. Clin Nutr 2018; 37: 2172-7.

14. Matłok M, Pędziwiatr M, Major P, et al. One hundred seventy-nine consecutive bariatric operations after introduction of protocol inspired by the principles of enhanced recovery after surgery $\left(\right.$ ERAS $\left.^{\circledR}\right)$ in bariatric surgery. Med Sci Monit 2015; 21 791-7.

15. Pisarska M, Malczak P, Major P, et al. Enhanced recovery after surgery protocol in oesophageal cancer surgery: systematic review and meta-analysis. PLoS One 2017; 12: e0174382.

16. Zychowicz A, Pisarska M, Łaskawska A, et al. Patients' opinions on enhanced recovery after surgery perioperative care principles: a questionnaire study. Videosurgery Miniinv in press; DOI: https://doi.org/10.5114/wiitm.2018.77261.

17. Pędziwiatr M, Kisialeuski M, Wierdak M, et al. Early implementation of Enhanced Recovery After Surgery (ERAS ${ }^{\circledR}$ ) protocol compliance improves outcomes: a prospective cohort study. Int J Surg 2015; 21: 75-81.

18. Pisarska M, Pedziwiatr M, Malczak P, et al. Do we really need the full compliance with ERAS protocol in laparoscopic colorectal surgery? A prospective cohort study. Int J Surg 2016; 36: 377-82.

19. Pedziwiatr M, Wierdak M, Nowakowski M, et al. Cost minimization analysis of laparoscopic surgery for colorectal cancer within the enhanced recovery after surgery (ERAS) protocol: a single-centre, case-matched study. Videosurgery Miniinv 2016; 11: 14-21.

20. Borisenko O, Lukyanov V, Debergh I, Dillemans B. Cost-effectiveness analysis of bariatric surgery for morbid obesity in Belgium. J Med Econ 2018; 21: 365-73.

21. Andalib A, Bouchard P, Bougie A, et al. Variability in bariatric surgical care among various centers: a survey of all bariatric surgeons in the Province of Quebec, Canada. Obes Surg 2018; 28: 2327-32.

22. Kuo LE, Simmons KD, Kelz RR. Bariatric centers of excellence: effect of centralization on access to care. J Am Coll Surg 2015; 221: 914-22.

23. Sartelli M, Catena F, Ansaloni L, et al. Complicated intra-abdominal infections in Europe: preliminary data from the first three months of the CIAO Study. World J Emerg Surg 2012; 7: 15.

24. Dambaugh LA, Ecklund MM. Progressive care of obese patients. Crit Care Nurse 2016; 36: 58-63.

25. Kostecka M, Bojanowska M. Problems in bariatric patient care challenges for dieticians. Videosurgery Miniinv 2017; 12: 207-15.

26. Whittemore AD, Kelly J, Shikora S, et al. Specialized staff and equipment for weight loss surgery patients: best practice guidelines. Obes Res 2005; 13: 283-9.
27. Lautz DB, Jiser ME, Kelly JJ, et al. An update on best practice guidelines for specialized facilities and resources necessary for weight loss surgical programs. Obesity 2009; 17: 911-7.

28. Nguyen NT, Moore C, Stevens CM, et al. The practice of bariatric surgery at academic medical centers. J Gastrointest Surg 2004; 8: 856-61.

Received: 12.10 .2018 , accepted: 12.12 .2018 . 